\title{
Pulmonary Strongyloidiasis in a Patient with Terminal Pulmonary Syndrome in Manabi Province, Ecuador: A Report Case
}

\author{
Juan Carlos Alava ${ }^{1 \#,}$, Susana Alava ${ }^{2 *}$ and Juan José Alava ${ }^{3 *^{*}}$ \\ ${ }^{1}$ Universidad Estatal del Sur de Manabí, Calle Santistevan entre Alejo Lascano y Mejia, Ecuador \\ 2Sociedadde Lucha Contrael Cáncer (SOLCA), Hospital Oncológico "Dr. Julio Villacreses Colmont", \\ Autopista del Valle Manabí Guillem Portoviejo, Ecuador \\ ${ }^{3}$ Institute for the Oceans and Fisheries, University of British Columbia, Canada \\ ${ }^{\#}$ These authors contributed equally to this work.
}

*Corresponding author: Juan José Alava, Institute for the Oceans and Fisheries, University of British Columbia, 2202 Main Mall, Vancouver, British Columbia, V6T 124, Canada

\begin{abstract}
Strongyloides stercoralis is a common nematode causing intestinal parasitosis in the Ecuadorian population, but cases of lung infection by this helminth have not been documented in Ecuador. We document the first case of pulmonary strongyloidias is caused by $S$. stercoralis filariform larvae in a male patient from Manabí Province (Ecuador), showing clinical symptoms of terminal pulmonary syndrome. Previous to the decease of the patient, the larvae were identified by the direct smear method of a fresh bronchial aspirate sample collected from the patient. Hyperinfection by filariform larvae (L3) was observed, exhibiting an abundance of up to four larvae per microscopic field. We suggest that an earlier treatment of the patient with a high spectrum anthelmintic could have saved his life. Pulmonary strongyloidiasis can be under diagnosed if the parasitological analysis of wet mounts of bronchial aspirate from patients suffering of chronic bronchitis and pulmonary syndrome to investigate the possible presence of S.stercoralis is not conducted. The training for microbiological screening using classic direct methods, as well as the constant investigation of this parasitosis and other helminthiases are still vital and relevant for public health personnel and microbiologists in developing countries in order to provide an early diagnosis of underdiagnosed parasitosis.
\end{abstract}

\section{Keywords}

Filariform larva, Pulmonary strongyloidiasis, Strongyloides stercoralis, Parasitosis, Ecuador, South America

\section{Introduction}

Pulmonary strongyloidiasis in humans is caused by Strongyloides stercoralis, which is one of the species of intestinal nematodes commonly found in tropical and subtropical countries in Latin America, mainly Colombia, Venezuela, Ecuador, Peru and Brazil, parts of the southeastern United States and other humid tropical regions of the world such as Asia (India and Southeast Asia, Bangladesh, Pakistan) and Africa (subSahara) [1-6]. It is estimated that between 30 and 100 million people are infected with $S$. stercoralis in the world, especially in tropical regions $[2,4,7]$. The parasite exhibits a complex dual life cycle involving two life phases, including a parasitic phase, in which humans are infected and serve as the primary host, and a nonparasitic phase, in which the larvae are found free in the environment. Adult worms can survive and reproduce in both the intestine of humans and soil, leading to a variety of possible routes of infection [8]. During the direct development, the eggs deposited by adult worms in the human intestine hatch as rhabditiform larvae (L1), which are passed in the fecal matter; under favorable conditions, the larvae mature in the soil in the form of filariform larvae (L3), which represents the infectious stage and are able to penetrate the skin of humans [8]. Rhabditiform larvae are also able to become non-parasitic adult worms living on the ground independently of humans throughout a free-living life cycle (i.e. indirect development as all the offspring of these free-living adults develop to infective L3) [9]; once the infective filariform larvae have penetrated the skin, they can travel to the lungs through the circulatory system, where they migrate into the airways (i.e. bronchi

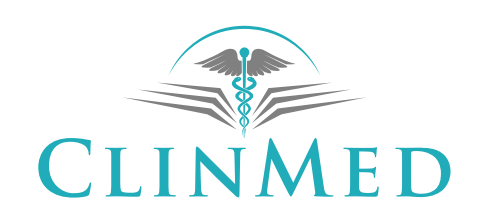

INTERNATIONAL LIBRARY
Citation: Alava JC, Alava S, Alava JJ (2018) Pulmonary Strongyloidiasis in a Patient with Terminal Pulmonary Syndrome in Manabi Province, Ecuador: A Report Case. Int J Trop Dis 1:012.

Accepted: December 06, 2018; Published: December 08, 2018

Copyright: (c) 2018 Alava JC, et al. This is an open-access article distributed under the terms of the Creative Commons Attribution License, which permits unrestricted use, distribution, and reproduction in any medium, provided the original author and source are credited. 


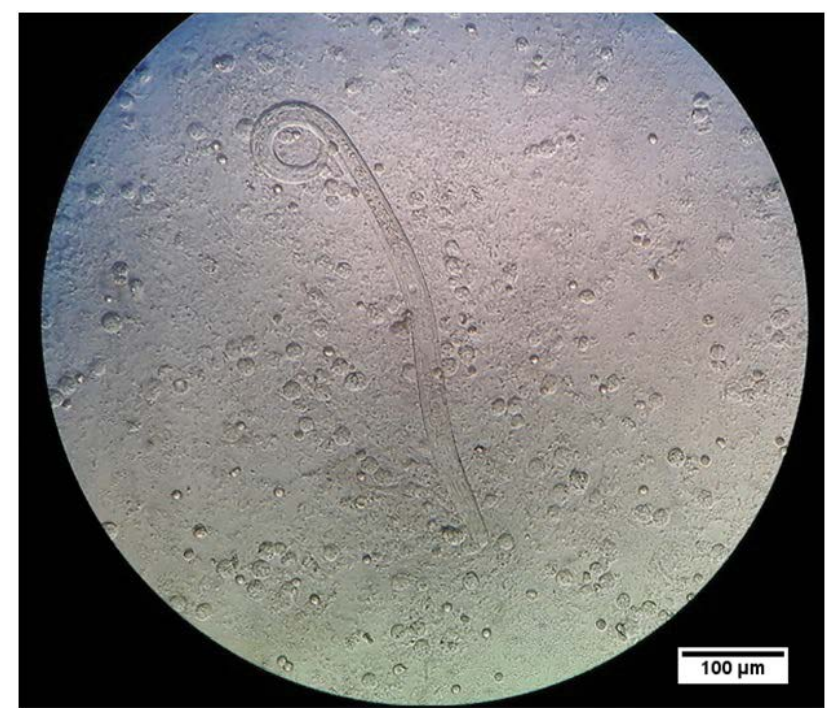

Figure 1: Strongyloides stercoralis filariform larvae (L3) observed in bronchial aspirate or throat swab (direct wet mount method; $10 \mathrm{X}$ by $10 \mathrm{X}$ magnification $=100$ ). Internal structure and esophagus are observed. An abundant presence of leukocytes is also observed.

and alveoli), moving through the trachea and pharynx, and eventually reaching the esophagus, in which the larvae are consequently swallowed and passed into the stomach and intestines, where mating occurs and the life cycle is completed [8].

Strongyloidiasis is now regarded as a neglected tropical disease emerging in many countries and is probably a parasitic disease underdiagnosed due to its low larval output and uncertain clinical signs $[8,10]$. In Ecuador, strongyloidiasis is a common intestinal parasitosis [11]; however, to the best of our knowledge, cases of pulmonary strongyloidiasis have been scarcely documented in the scientific literature despite the severity and health complications involved with this parasitosis as reported in several clinical cases elsewhere [12-20]. In this study, we report the identification of and hyperinfection by $S$. stercoralis in a sample obtained from a bronchial aspirate of a patient suffering from acute pulmonary syndrome in Portoviejo, Ecuador.

\section{Case Description}

A 56-year-old patient (MOB) with symptoms of a presumable pulmonary syndrome with chronic bronchitis (bronchopneumonia) was hospitalized in the intensive therapy care unit for 30 days between February and March 2014 at the hospital of the Ecuadorian Social Security Institute (IESS), Portoviejo (Manabí, Ecuador). The patient exhibited symptoms associated to pulmonary syndrome including acute respiratory (breathing) difficulty of torpid progression, cough and mucus (sputum) production. The medical treatment of the patient involved administration of omeprazole ( $40 \mathrm{mg}$ intravenously [IV] every 8 hours) and metoclopramide ( 1 ampule IV every 8 hours); the patient did not received corticosteroid drugs treatment as part of the therapy. Initially and for most of the inpatient

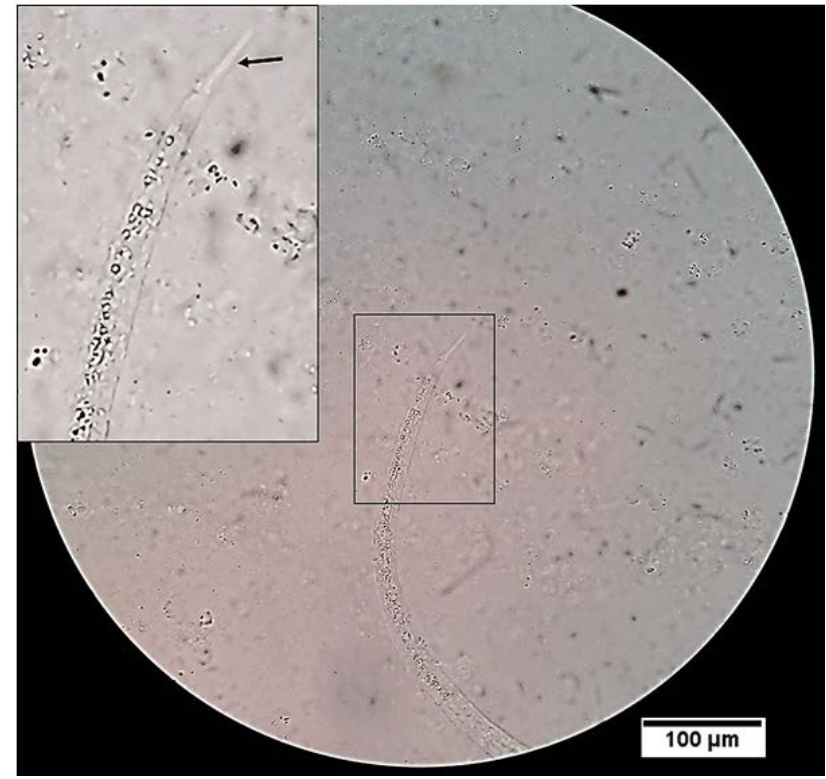

Figure 2: Photo of the notched tail of Strongyloides stercoralis filariform larvae (L3) as a diagnostic feature of this parasite observed in bronchial aspirate (direct wet mount method; $10 \mathrm{X}$ by $10 \mathrm{X}$ magnification $=100$ ). The black rectangle and arrow indicate the location of the larvae tail in the microscopic field.

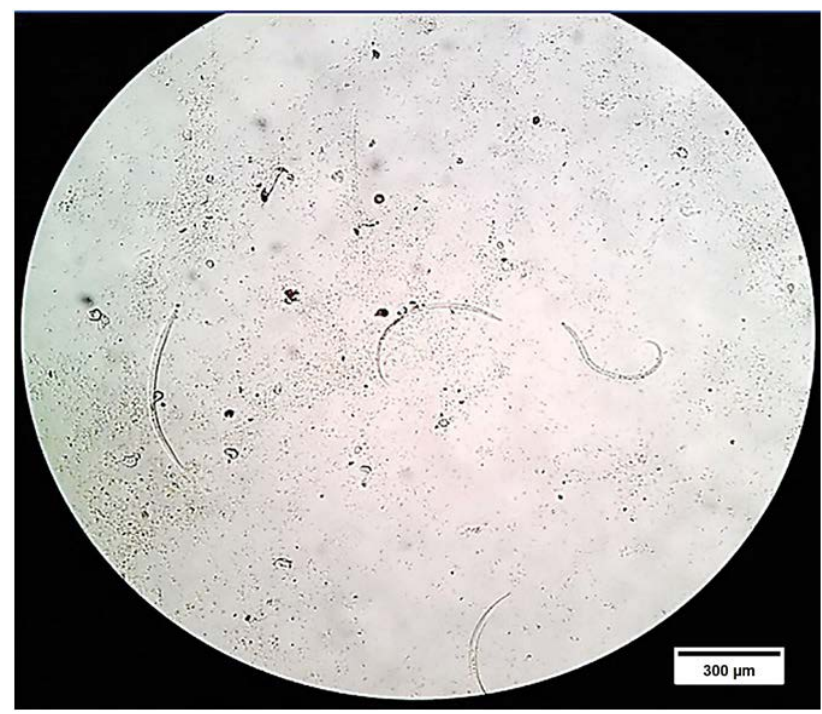

Figure 3: Abundance of Strongyloides stercoralis filariform larvae (L3) in bronchial aspirate, in which four larvae per microscopic field are observed (Olympus, 10X).

hospitalization, the pathogenic agent causing this syndrome was not clinically diagnosed and the patient died of cardiorespiratory arrest on day 30. On day 29 (March 15, 2014) at 19:00, a bronchial aspirate sample obtained from the patient was received and prepared by the direct wet mount method (DX) with the addition of $10 \%$ potassium hydroxide $(\mathrm{KOH})$. In the microscopic analysis, filariform larvae (L3) were observed and identified as S. stercoralis filariform larvae (infective stage; Figure 1) based on the internal structure, the morphology of the larvae with a characteristic notched tail and a filariform esophagus (Figure 2). During the direct microscopic diagnosis, the larvae abundance was up to four larvae per microscopic field (Figure 3), with 
an associated leukocytes' abundance ranging from 80 to 100 cells per field (Figures 1, Figure 2 and Figure 3), indicating evidence of an inflammatory reaction due to the abundant presence of larvae (i.e. hyperinfection). Blood culture of two samples revealed the presence of Pseudomonas aeruginosa and Gram-staining examination was positive for Gram negative rods.

The filariform larvae (L3) observed in the fresh preparation were recorded with a video (Samsung Galaxy tab 3, 7", 3MP FF + camera, 1.3 MP Full HD, available at https://www.instagram.com/p/xVh7crm $\mathrm{fH} 2 /$ ?fbclid=IwAR3Yt3BO01tLkf-S7OKdXSUeRNfwllgO0ECbC4CqDsPbf4jCqFjfBdOOeE) played from the microscope's ocular lens (Olympus) and using the $10 \mathrm{X}$ dry objective (10X) (i.e. 10X by 10X magnification $=100$ ).

\section{Discussion}

This study is the first documented report of a case of pulmonary strongyloidiasis due to hyperinfection larvae of $S$. stercoralis in Manabí (Ecuador). The larvae hyperinfection probably triggered a pulmonary syndrome with asthma, chronic bronchitis, eosinophilia and pulmonary infiltration, as reported in the literature $[12,13]$.

Although a chest X-ray's lung image and highresolution computerized tomography were not performed before or after the death of the patient, the direct microscopic diagnosis of bronchial aspirates revealed the hyperinfection by $S$. stercoralis. In a fatal case of pulmonary strongyloidiasis involving a 65-year-old Korean male patient, chest computed tomography revealed very unusual findings, including multiple micronodules ( $<3 \mathrm{~mm}$ in diameter) and faint ground-glass opacities in both lungs [14]. Disseminated strongyloidiasis can also frequently develop in patients with immunodeficiency caused by poor diet, drug therapy (including steroid therapy) for autoimmune diseases, chronic alcoholism, older age, diabetes mellitus, and collagen disease $[15,16]$. As an example, a 58-years-old male suffering of Crohn's diseases showed septic shock caused by pulmonary strongyloidiasis, which was diagnosed with bronchial washing cytology and Strongyloides antibodies serology [16]. Following treatment with ivermectin, the health of the patient improved, significantly [16].

While pulmonary strongyloidiasis has been documented in the international literature in different parts of the world $[3,12-17]$, there are no documented records of pulmonary strongyloidiasis in Ecuador published in the international medical literature. However, we cannot rule out the possibility that $S$. stercoralis associated to this type of parasitic disease has already been observed in this country, but without any refereed publication. There should be noted that the diagnosis and finding of $S$. stercoralis in routine parasitological analysis of stools and the relative prevalence of intestinal strongyloidiasis in the
Ecuadorian population are common [11]. For example, Alvarez, et al. [18] reported the diagnosis of chronic and active duodenitis with parasitosis by $S$. stercoralis in a 44-years-old patient in Quito (capital city of Ecuador), but infection in the lungs was not found.

In Colombia, Cataño and Pinzón [17] recently reported filariform Strongyloides larvae in bronchial alveolar lavage of a patient. Similarly, Vélez-Londoño and Sandoval [19] found mobile larvae of S. stercoralis in the direct examination of bronchoalveolar lavage fluid of a 31-years-old patient from Buenaventura (Valle, Colombia). Arteta, et al. [20] report filariform larvae, identified as S. stercoralis, during a direct microscopic study of alveolar bronchiole sample in an immunocompromised 18-years-old patient (HIV positive) in Uruguay. As a parasitic infection, pulmonary strongyloidiasis must be considered in the differential diagnosis of non-resolving pneumonia, particularly in immunocompromised patients [16].

These findings indicate that this pulmonary helminthiasis is more common than previously thought and is found in South American countries. However, the diagnosis of lung infection by $S$. stercoralis can often be ignored and undiagnosed, particularly in patient populations with a high prevalence of this parasitic disease and chronic lung disease [21].

It is expected that new diagnostic methods and epidemiological studies will improve control efforts for the prevention and treatment of strongyloidiasis [9]. An important clinical strategy to consider is the direct parasitological analysis of fresh bronchial aspirates in advance when patients showing pulmonary syndrome are admitted to the hospital. In this context, the possible treatment of the patient case reported here may have started with a prescription using a high spectrum anthelmintic such as 400-200 mg of Albendazole [8,22], $10 \mathrm{mg}$ of Ivermectin [13] or $200 \mu \mathrm{g}$ (Ivermectin)/ $\mathrm{kg}$ $[16,23]$ to remove the larvae and foster the possible recovery of the patient.

\section{Conclusion}

The parasitological diagnosis of pulmonary strongyloidiasis by $S$. stercoralisis a key step for the earlier treatment of this parasitosis. Of paramount importance is the analysis of fresh sputum or aspirated bronchial lavage to investigate and/or exclude the presence of $S$. stercoralis in patients from endemic areas of strongyloidiasis with a high epidemiological risk history, and showing pulmonary syndromes or bronchitis. While the strongyloidiasisis a parasitosis of particular attention in tropical nations, this disease is not a priority public health subject covered by epidemiological surveillance in Ecuador and other countries despite their frequency. Therefore, health monitoring programs and more research are required to undertake appropriate parasitological diagnoses 
and understand the mechanisms of severe clinical manifestations of human strongyloidiasis.

\section{Acknowledgements}

We thank and dedicate this contribution in memory of our mentor and late father, Dr. Juan José Alava Párraga (1942-2008), who pioneered studies on tropical parasitology and clinical microbiology in the province of Manabí and one of the first researchers in tropical medicine in Ecuador. Special thanks to Dr. Gustavo Dominguez (Faculty of Life Sciences, Superior Polytechnic School-ESPOL, Guayaquil, Ecuador) for providing the scale bar for measurements in the photos.

\section{References}

1. Genta RM (1989) Global prevalence of strongyloidiasis: Critical review with epidemiologic insights into the prevention of disseminated disease. Rev Infect Dis 11: 755-767.

2. Grove DI (1989) Historical introduction. In: Grove DI, Strongyloidiasis: A major roundworm infection of man. Taylor \& Francis, Philadelphia, Pennsylvania.

3. Pillai KR, Nair GR, Amma NS, Nair MK (1993) Diagnosis of pulmonary strongyloidiasis by sputum cytology: A Case Report. Indian J Pathol Microbiol 36: 489-491.

4. Grove DI (1994) Strongyloidiasis: A conundrum for gastroenterologists. Gut 35: 437-440.

5. Adedayo O, Grell G, Bellot P (2002) Hyperinfective strongyloidiasis in the medical ward: Review of 27 cases in 5 years. South Med J 95: 711-716.

6. Puthiyakunnon S, Boddu S, Li Y, Zhou X, Wang C, et al. (2014) Strongyloidiasis-An insight into its global prevalence and management. PLoS Negl Trop Dis 8: e3018.

7. Olsen A, van Lieshout L, Marti H, Polderman T, Polman $\mathrm{K}$, et al. (2009) Strongyloidiasis-the most neglected of the neglected tropical diseases? Trans R Soc Trop Med Hyg 103: 967-972.

8. Farrar J, White NJ, Hotez PJ, Junghanss T, Lalloo D, et al. (2014) Manson's Tropical Infectious Diseases. (23 ${ }^{\text {rd }}$ edn), Saunders Ltd, Elsevier.

9. Yamada M, Matsuda S, Nakazawa M, Arizono N (1991) Series-specific differences in heterogonic development of serially transferred free-living generations of Strongyloides planiceps and Strongyloides stercoralis. J Parasitol 77: 592-594.
10. Montes M, Sawhney C, Barros N (2010) Strongylodies stercoralis: There but not seen. Curr Opin Infect Dis 23: 500-504.

11. Fernández T (1990) Texto de Medicina Tropical: Enfermedades Tropicales en el Ecuador. Universidad de Guayaquil, Guayaquil, Ecuador, 370.

12. Nwokolo C, Imohiosen EA (1973) Strongyloidiasis of respiratory tract presenting as asthma. Br Med J 2: 153154.

13. Jayaprakash B, Sandhya S, Anithakumari K (2009) Pulmonary Strongyloidiasis. J Assoc Physicians India 57: 535-536.

14. Bae K, Jeon KN, Ha JY, Lee JS, Na BK (2018) Pulmonary strongyloidiasis presenting micronodules on chest computed tomography. J Thorac Dis 10: E612-E615.

15. Siddiqui AA, Berk SL (2001) Diagnosis of Strongyloides stercoralis infection. Clin Infect Dis 33: 1040-1047.

16. Abdalla $M$, Sinyagovskiy $P$, Mohamed $W$, Abdelghani $A$ (2018) Pulmonary strongyloidiasis causing septic shock in a patient with Crohn's disease. Respir Med Case Rep 24: 52-54.

17. Cataño JC, Pinzón MA (2012) Strongyloides Pneumonia. Am J Trop Med Hyg 87: 195.

18. Álvarez AS, Salazar AJ, Salazar AE, Vivar DN (2010) Estrongiloidiosis. A propósito de un caso clínico. Rev Mex Patol Clin 57: 209-211.

19. Vélez-Londoño JD, Sandoval MG (2007) Fracaso del tratamiento de estrongiloidiasis con ivermectina. Infectio 11: $95-97$.

20. Arteta Z, Mencía X, Larre Borges A, Gezuele E, Calegari L (2006) Hiperinfección por Strongyloides stercoralis (Bavay 1876; Stiles y Hassall 1902) en Uruguay. Rev Méd Urug 22: 226-230.

21. Saito A (1995) Strongyloidiasis: Epidemiology, clinical manifestations and new methods for diagnosis and treatment. J Infect Chemother 1: 98-106.

22. Domínguez A, Alzate A (1988) La efectividad del Albendazol en el tratamiento de la estrongiloidiasis en niños. Biomédica 8: $43-45$.

23. Arbeláez V, Angarita Ó, Gómez M, Sprockel J, Mejía M (2007) Presentación de caso clínico interinstitucional: Gastroduodenitis severa secundaria a hiperinfección por Strongyloides stercolaris en un hombre joven. Rev Col Gastroenterol 22: 118-125. 